\title{
Characterization of Sludge From Iron Ore Processing and Properties of Mortar Prepared by Full Replacement of Natural Silica Sand
}

\author{
Alena Sičáková and Marek Kováč \\ Technical University of Košice, Faculty of Civil Engineering, 04200 Košice, Slovakia
}

\begin{abstract}
This paper focuses on the use of sludge, which is currently a landfilled sand-like material left over from the processing of iron ore (IOP), representing an environmental burden. The incorporation of the material into some building mixtures like mortar or concrete can bring both environmental and technical benefit through the improvement of some properties of final mixture. Through the realization of the experiment programme, the authors have contributed to the knowledge about IOP and have determined the impact of this material on the properties of mortar mixture. This material is characterized using chemical, mineralogical, and granulometric analysis and then applied as $100 \%$ replacement of silica sand in standard mortar mixture. Basic physical-mechanical parameters (water demand, flexural strength, compressive strength) were tested. For the strength characteristics, both the samples with IOP sludge and samples with standardized sand (reference sample) were subjected to testing for a long-term period (14, 28, 270, and 365 days). Moreover, the capillary moisture was measured for 28-day old samples. Mortar prepared with IOP sludge shows lower compressive strength compared to the reference mixture throughout the overall time development, although the values themselves are sufficient for practical application. The flexural strength was found to be even better. The performance of the IOP sludge can be deemed as promising for practical applications when used in cement mortar.
\end{abstract}

\section{Introduction}

The use of cement-based mixtures as a tool for effective recycling has been actively researched for the last few years. Examples of these efforts include materials derived from building demolitions, residues from ceramic raw material, residues from extraction, and residues from processing/liquidation of rocks or aggregates. Experimental studies [1-3] confirm the successful use of these materials as partial or complete replacement of natural aggregates as filler in concrete.

Work [4] can be mentioned as an example describing an investigation of quarry dust and marble sludge as a replacement for natural aggregates in concrete. The results of this study show a positive impact on the resulting concrete parameters-higher compressive strength and better water resistance. Other examples of experimental studies use foundry sand, quarry sand $[5,6]$, ash from sewage sludge [7], and even glass [8].

As for sludge, various kinds have been investigated for application as filler in mortars: sludge from readymixed concrete plants as a substitute for limestone fillers [9], sludge from water treatment plants with different levels of replacement for natural sand [10], and marble powder as a replacement for conventional river sand in cement mortars [11].
The presented applications do not show significant limitations for use as filler in cement composites. Relatively worse results in some cases do not mean disqualification for utilization; they only represent a recommendation for application in materials having lower but sufficient parameters.

This paper presents the results of the characterization of IOP sludge and the results of testing the mortars, with full replacement of natural sand by dewatered sludge from the processing of iron ore (IOP sludge). Basic physical-mechanical parameters (water demand, flexural strength, compressive strength, capillary moisture content) were tested in long-term time-development (14, 28, 270, and 365 days) for samples with both IOP sludge and silica sand (reference sample). Moreover, the capillary moisture was measured for 28-day old samples. The choice of properties was made with regard to performance characteristics of mortars, with a direct effect on their durability.

\section{Materials and methods}

For the characterization of IOP sludge, the chemical, mineralogical, and grain-size distribution analyses were carried out. For mortar preparation, ordinary Portland cement (CEM I 42.5), silica sand (fraction 0/0.5), and 
sludge from iron ore (siderite) processing (IOP sludge) were used. The sludge was in de-watered form.

\subsection{Characterization of IOP sludge}

This material was then stored in ponds, with no commercial use.

Chemical composition was found by X-ray fluorescence analysis (XRF) using SPECTRO iQ II (Ametek, Germany) with SDD silicon drift detector of $145 \mathrm{eV}$ resolution at 10,000 pulses. Results are given in Table 1. It is clear that the IOP sludge is rich in mainly $\mathrm{SiO}_{2}$ and $\mathrm{Fe}_{2} \mathrm{O}_{3}$.

Table 1. Results of XRF chemical analysis of IOP sludge.

\begin{tabular}{|c|c|}
\hline Oxides & $\begin{array}{c}\text { Concentration } \\
{[\%]}\end{array}$ \\
\hline $\mathrm{MgO}$ & 1.8 \\
\hline $\mathrm{Al}_{2} \mathrm{O}_{3}$ & 5.6 \\
\hline $\mathrm{SiO}_{2}$ & 39.8 \\
\hline $\mathrm{CaO}$ & 0.7 \\
\hline $\mathrm{Fe}_{2} \mathrm{O}_{3}$ & 33.2 \\
\hline $\mathrm{K}_{2} \mathrm{O}$ & 1.1 \\
\hline $\mathrm{MnO}$ & 1.8 \\
\hline $\mathrm{TiO}_{2}$ & 0.1 \\
\hline $\mathrm{P}_{2} \mathrm{O}_{5}$ & 0.1 \\
\hline $\mathrm{SO}_{3}$ & 0.3 \\
\hline others & 15 \\
\hline
\end{tabular}

Mineralogical analysis was done by the XRD method-diffractometer Bruker D2 Phaser (Bruker AXS, $\mathrm{GmbH}$, Germany) in Bragg-Brentano geometry (configuration Theta-2Theta), using 1.54060- $\AA \mathrm{CuK} \alpha$ radiation, $\mathrm{Ni} \mathrm{K} \beta$ filters, and scintillation detector at a voltage of $30 \mathrm{kV}$ and $10 \mathrm{~mA}$ current. As shown in Figure 1 , IOP sludge is mainly formed by quartz, siderite, and nontronite minerals.

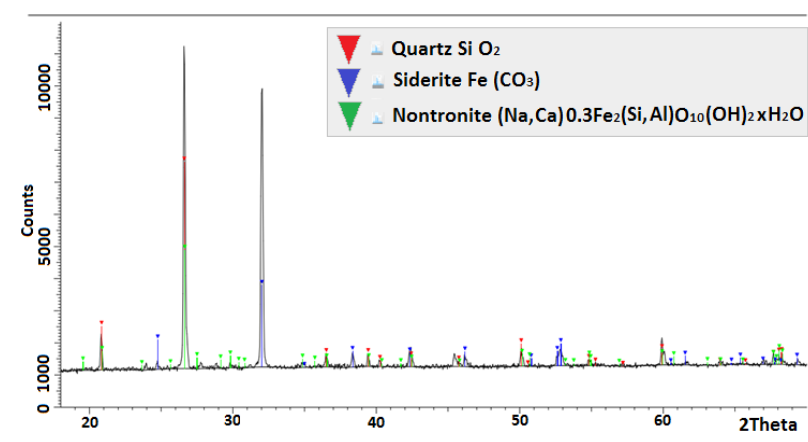

Figure 1. XRD mineralogical analysis of IOP sludge

Grain-size distribution was determined using standard sieve analysis according to [12]. Results are given in Figure 2 while being compared with silica sand. IOP sludge is finer than silica sand, it contains $97 \%$ of grains up to $0.5 \mathrm{~mm}$ while $58.7 \%$ of the grains are up to $0.125 \mathrm{~mm}$ in size.

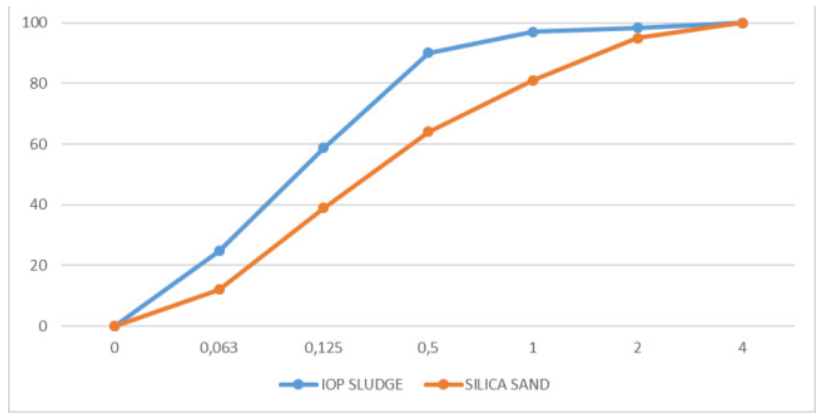

Figure 2. Grain-size distribution of IOP sludge and silica sand

\subsection{Mixture proportioning and testing methods}

Two mixtures are given here: one with $100 \%$ replacement of fine natural aggregate by the IOP sludge and the other (reference mixture) with natural silica sand only. The mixture proportions of mortars are given in Table 2 . Mixtures were prepared to maintain the same consistency; this is why the water amounts are different.

Beam samples of $40 \times 40 \times 160 \mathrm{~mm}$ were prepared and cured under standard conditions $\left(20^{\circ} \mathrm{C}\right.$, water curing).

Table 2. Composition of mortars.

\begin{tabular}{|c|c|c|c|}
\hline Component & Units & $\begin{array}{c}\text { Reference } \\
\text { mortar }\end{array}$ & $\begin{array}{c}\text { IOP sludge } \\
\text { mortar }\end{array}$ \\
\hline $\begin{array}{c}\text { CEM I 42.5 } \\
\text { R }\end{array}$ & {$\left[\mathrm{kg} / \mathrm{m}^{3}\right]$} & 500 & 500 \\
\hline Water & {$\left[\mathrm{kg} / \mathrm{m}^{3}\right]$} & 250 & 400 \\
\hline Silica sand & {$\left[\mathrm{kg} / \mathrm{m}^{3}\right]$} & 1510 & - \\
\hline IOP sludge & {$\left[\mathrm{kg} / \mathrm{m}^{3}\right]$} & - & 1510 \\
\hline w/c & - & 0.5 & 0.8 \\
\hline
\end{tabular}

The following parameters were tested:

- The water demand to keep the same consistency, expressed by penetrator immersion according to [13]. The water demand was expressed in $\%$.

- Flexural strength and compressive strength after 14, 28, 270 , and 365 days of hardening, according to [14].

- Capillary moisture up to $90 \mathrm{~min}$. of immersion, according to [15]. Capillary moisture content was calculated according to Formula (1):

$$
m_{c}=A_{w} \cdot \sqrt{ } t
$$

where:

$\mathrm{A}_{\mathrm{w}}$ - water absorption coefficient $\left[\mathrm{kg} /\left(\mathrm{m}^{2} \cdot \mathrm{h}^{0.5}\right)\right]$

$$
\mathrm{t} \text { - time }[\mathrm{s}]
$$




\section{Results and discussion}

\subsection{Water demand}

The mixture containing sludge as an overall substitution of natural silica sand shows higher water demand to maintain the same workability compared to the reference mixture (see Tab. 2). The water demand is $60 \%$ higher compared to that of the reference mortar mixture. This complies with the very fine character of IOP sludge. Similar results are reported by [9], who use the slurry from ready-mixed concrete plants in mortars as limestone filler substitute; the authors report a decrease in the workability of the fresh state mortar and recommend higher superplasticizer content.

\subsection{Flexural strength}

Values of flexural strength are given in Table 3, while the time development is expressed in Figure 3. The mixture containing IOP sludge as an overall substitution of silica sand shows slightly higher flexural strength compared to the reference mixture. This is quite surprising, since the $\mathrm{w} / \mathrm{c}$ ratio is not same (the IOP-sludge mortar contains more water). The beneficial influence of sludge seems to outweigh the adverse impact of water. Values from 3.5 $\mathrm{MPa}$ (14 days) to $6.7 \mathrm{MPa}$ (28 days) are sufficient for practical uses. However, the long-term value (365 days) is lower (4.5 MPa), so it seems to be necessary to test this material for a longer time to check whether or not some deterioration takes place later. These results are in a regime different from that given by [10], who uses sludge from water treatment plants with different levels of replacement of natural sand. He shows the flexural strength of mortars to have no significant difference in relation to the strength of the reference mortars over time.

\subsection{Compressive strength}

Values of compressive strength are given in Table 4, while the time development is expressed in Figure 4. An illustration of IOP sludge mortar structure, visible after the compressive strength test, is shown in Figure 5. The mixture containing IOP sludge as an overall substitution of silica sand shows lower compressive strength compared to the reference mixture. However, it cannot be attributed only to this substitution, since the w/c ratio is not same (the IOP-sludge mortar contains more water and thus its negative impact can be expected). On the other hand, [11] explain that the gain in strength is due to reactions being so significant that they overcome the negative effect of greater $\mathrm{w} / \mathrm{c}$ ratio in mortar mixes, but only up to $60 \%$ substitution. When marble powder is used to substitute more than $60 \%$ of sand, the pores formed due to excess of water are sufficient to reduce the compressive strength (however, these results are for the marble powder as fine aggregate). In our experiment, the substitution is $100 \%$.

However, the strength values themselves are important, ranging from $24.0 \mathrm{MPa}$ (14 days) to $31.5 \mathrm{MPa}$ (28 days); despite the high $\mathrm{w} / \mathrm{c}$ ratio, these values are promising for practical usage. As in the case of flexural strength, the long-term compressive strength (365 days) starts becoming lower. Thus, it also seems to be necessary to test this material for a longer time to check whether or not some deterioration takes place later.

Table 3. Flexural strength of mortars.

\begin{tabular}{|c|c|c|c|c|}
\hline \multirow{2}{*}{ Sample } & \multicolumn{4}{|c|}{ Flexural strength $\mathrm{f}_{\mathrm{fl}}[\mathrm{MPa}]$ / days } \\
\cline { 2 - 5 } & 14 & 28 & 270 & 365 \\
\hline $\begin{array}{c}\text { Reference } \\
\text { mortar }\end{array}$ & 3.0 & 5.0 & 5.5 & 5.7 \\
\hline $\begin{array}{c}\text { IOP sludge } \\
\text { mortar }\end{array}$ & 3.5 & 5.5 & 6.7 & 4.5 \\
\hline
\end{tabular}

Table 4. Compressive strength of mortars.

\begin{tabular}{|c|c|c|c|c|}
\hline \multirow{2}{*}{ Sample } & \multicolumn{4}{|c|}{ Compressive strength $\mathrm{f}_{\mathrm{c}}[\mathrm{MPa}]$ / days } \\
\cline { 2 - 5 } & 14 & 28 & 270 & 365 \\
\hline $\begin{array}{c}\text { Reference } \\
\text { mortar }\end{array}$ & 38.8 & 42.1 & 43.8 & 44.5 \\
\hline $\begin{array}{c}\text { IOP sludge } \\
\text { mortar }\end{array}$ & 24.0 & 29.5 & 31.5 & 25.5 \\
\hline
\end{tabular}

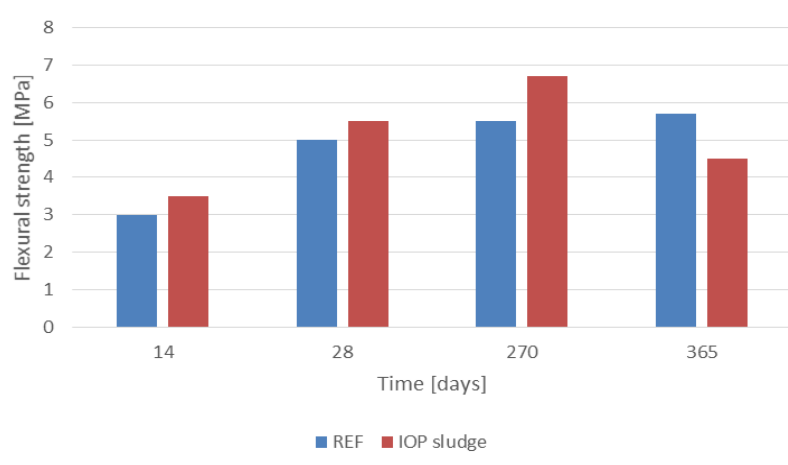

Figure 3. Time development of the flexural strength of mortars.

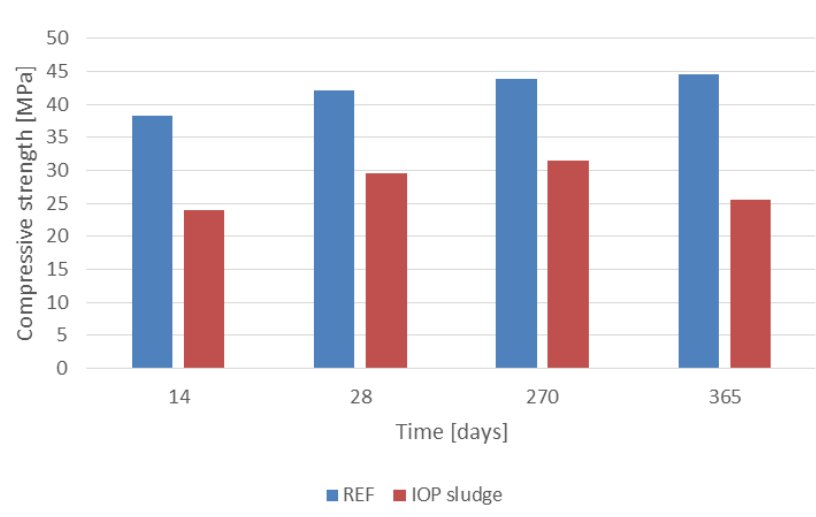

Figure 4. Time development of the compressive strength of mortars. 


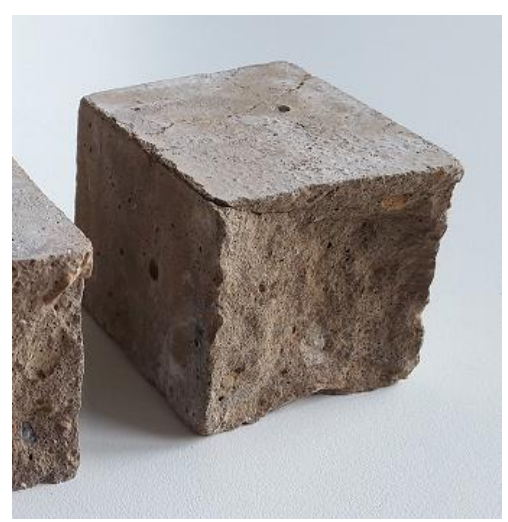

Figure 5. Illustration of IOP sludge mortar structure.

\subsection{Capillary moisture content}

Despite the quite major difference in w/c ratio $(0.5 \mathrm{vs}$ 0.8 ), the difference in capillary moisture content between reference mortar and IOP-sludge mortar is not so big, as shown in Figure 6. After 90 minutes of immersion in water, the mc of IOP-sludge mortar was found to be $16 \%$ greater than the $\mathrm{mc}$ of the reference mortar.

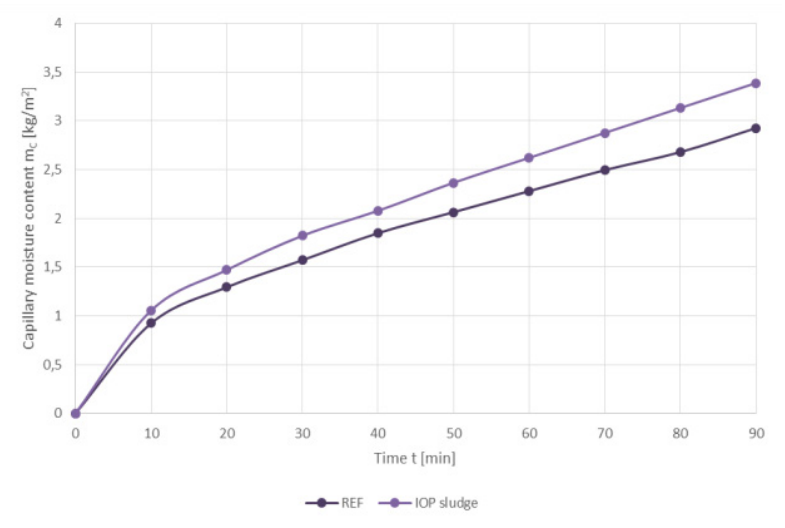

Figure 6. Capillary moisture content of samples.

\section{Conclusion}

The paper presents the results of the characterization of sludge from the processing of IOP sludge (chemical, mineralogical, and grain-size analysis) and the results of testing mortars (water demand, flexural strength, compressive strength, capillary moisture content), with full replacement of natural sand. Mechanical parameters were tested in long-term time-development $(14,28,270$ and 365 days) for samples with both IOP sludge and silica sand (reference sample).

The following main conclusions can be formulated for IOP sludge and IOP sludge mortars:

- The IOP sludge is a fine-granular material of grain-size $0 / 0.5$, consisting mainly of $\mathrm{SiO}_{2}(39.8 \%)$ and $\mathrm{Fe}_{2} \mathrm{O}_{3}$ $(33.2 \%)$, while formed mainly by quartz, siderite, and nontronite minerals.
- The water demand is $60 \%$ higher compared to the reference mortar mixture, while flexural strength is higher than that of reference sample (5.5MPa vs $5.0 \mathrm{MPa}$ in 28-day hardening). Compressive strength is lower than that of the reference sample (29.5MPa vs $42.1 \mathrm{MPa}$ in $28-$ day hardening), and capillary moisture content is $16 \%$ greater than that of the reference mortar.

- In light of the actual w/c ratio, the results of hardened mortar properties are promising; as seen in the case of flexural strength, the beneficial influence of sludge seems to be able to outweigh the adverse impact of water.

- Since a decrease in strengths was observed when testing 365-day old samples, durability characteristics should be tested for a longer time to determine whether or not some deterioration takes place later.

Further optimization of properties should be oriented towards some effective application of plasticizers or changing the replacement level of IOP sludge.

\section{Acknowledgement}

The project presented in this article has been carried out within the project of Slovak Scientific Grant Agency VEGA (grant number 1/0524/18) and the project NFP 26220220051, supported by the EU Structural funds.

\section{References}

1. M. Ledererova, Wst. For. 1, 29-40 (2012)

2. D. Matias, J. Brito, Constr. Build. Mater. 44, 101109 (2013)

3. C. Medina, M. Frias, Constr. Build. Mater. 31, 10931097 (2012)

4. T. Naik, V. Patel, J. Mater. Civ. Eng. 6, 1093-1097 (1994)

5. S. Kenai, D. Djeziri, Des. Technol. Refurb. Manag. Build. 140-141 (2010)

6. B. Felekoglu, Resour. Conserv. Recycl. 51, 770-791 (2007)

7. M. Kosior-Kazberug, Polish J. Environ. Stud. 20, 365-370 (2011)

8. M. Mavrodlidou, D. Candengue, Proc. 12th Int. Conf. Environ. Sci. Technol. 1-8 (2011)

9. M. Audo, P.Y. Mahieux, P. Turcry, Constr. Build. Mater. 112, 790-799 (2016)

10. J.J. de Oliveira Andrade, M.C. Wenzel, G.H. da Rocha, S.R. da Silva, J. Clea. Prod. 192, 159-168 (2018)

11. K.S.A. Kabeer, A.K. Vyas, Constr. Build. Mater. 165, 321-332 (2018)

12. EN 933-1 Tests for geometrical properties of aggregates. (2012)

13. EN 1015-4 Methods of test for mortar for masonry. (1998)

14. EN 1015-11 Methods of test for mortar for masonry. (1999)

15. EN 1015-18 Methods of test for mortar for masonry. (2002 